\title{
An Empirical Investigation of Factors Influencing the Adoption Decision of Mobile Agriculture in Nigeria
}

\author{
Oladotun Okediran \\ Dept. of Computer Engineering \\ Ladoke Akintola University of Tech. \\ Ogbomoso Nigeria
}

\author{
Wajeed Wahab \\ Dept. of Computer Engineering \\ Ladoke Akintola University of Tech. \\ Ogbomoso Nigeria
}

\author{
Olusola Ogunjinmi \\ Dept. of Agric. Education \\ Emmanuel Alayande College of \\ Education, Oyo, Nigeria
}

\begin{abstract}
In this paper, an extended technology acceptance model (TAM) was presented to investigate the factors that have effects on the intention to adopt and use mobile agriculture (m-Agriculture). The paper's main objective is to survey the usage of mobile phones in agriculture and examine the prospects and intents toward m-Agriculture among smallholder famers in South-western Nigeria. A survey was conducted by administering a questionnaire containing 25 items. The data collected from the survey was used to empirically test the proposed model for the adoption and use of m-Agriculture. The model was evaluated using the partial least squares structural equation analysis. The results of the evaluation showed that all the variables have significant effect on the farmers' behavioural intention to use m-Agriculture. In concluding the paper, the authors proposed an m-Agriculture architecture whose contents delivery channels are based on voice, short message service (SMS) and Unstructured Supplementary Service Data (USSD) of basic/feature phones with the aim of providing a digital platform for enhancing agricultural productivity, efficiency and sustainability.
\end{abstract}

\section{Keywords}

Mobile agriculture, Technology acceptance model, Smallholder farmers, Job relevance, Performance expectancy, Perceived compatibility, Perceived price value, Social influence

\section{INTRODUCTION}

In Nigeria, agriculture is mainly conventional and practiced by smallholders and pastoralists. This type of agricultural practice is characterized by low productivity and being largely rain-fed. The attendant problems being faced by these farmers are multifaceted including: sectional and meagre farm sizes, which give rise to diseconomies of scale and low productivity; insufficient knowledge and proficiency in contemporary farming methods (poor agricultural practices) and best managerial techniques; ineffective delivery of information; inaccessibility to vital information; lack or inadequate information on best agricultural practices; insufficient farmers' experience in marketing; lack of market facilitation; abysmal articulation between farmers, markets, researchers and extension workers; inadequate information on inputs; lack of financial interventions amongst other challenges [1]. It was also noted by [2] that the lopsided spread of infrastructures (such as roads, telecommunication, government services to mention but a few), debilitated infrastructures, underfunding of rural areas, inadequate access to markets and unjust market situations, poor access to appropriate technologies, expensive production and transport costs, and so on are evident problems faced by smallholder farmers in Nigeria.

Furthermore, majority of farmers in Nigeria and sub-Saharan
Africa have access to an array of information sources which serves as reference for regular information on agriculture. The most popular amongst these sources include government agricultural extension agents, fellow farmers, produce traders, farmer input brokers, families, radio, television, newspapers, seed merchants and so on [3]. Most of the information from these sources may not be of assistance, up to date or accurate. Also, the quality and relevance of information made available by them can be extremely inconsistent. Many a times, information made available for farmers by these sources may even be biased against the farmer; as an instance, required information is twisted in favour of more informed persons or groups which often compel disadvantaged farmers to trade their harvests below reasonable value. Most farmers as a result of the aforementioned barriers coupled with lack access to consistent and reliable information for a large majority of their needs have to habitually depend on the combination of these diverse but conflicting information. Also, there is high reliance on conventional knowledge, incidents and estimations by these farmers when making decisions. Another major constriction is that in situations where acceptable and appropriate information on market prices are available, farmers, most times are unable to take advantage of prospective pricing benefits that exist between markets due to their inability to convey their farm produce to the markets with higher prices [2].

Encouragingly, diverse Information and Communications Technology (ICT) solutions have emerged, which are progressively more available in even the remotest localities to aid in surmounting this information gaps and improve the business of agriculture dynamically [3]. Arguably, ICT can boost the efficiency, output and sustainability of the agriculture industry, by making available and accessible to farmers, information easily and economically with a vision of improving farm operations, marketing and financing [4]. The effective, efficient and simple usage of ICT can satisfy several information needs that could improve the livelihood of smallholders. ICT has been proven to been an essential resource for growth and development of economies as it can bridge the important knowledge gap between stakeholders.

The conveyance of agricultural information and knowledge services by means of contemporary information and communication tools and technologies for agricultural marketing, logistics, operations, products pricing, agricultural research, planning, extension services, production, monitoring, marketing and trade and financial inclusion that boost agricultural productivity, efficiency and sustainability all falls under the definition of electronic agriculture (eAgriculture). The corresponding porting of these applications to mobile devices such as Smartphone and tablets is termed $\mathrm{m}$-Agriculture. E-Agriculture presents a high prospect of supplementing conventional delivery of services and channels 
of communication in manners that widen agriculture organization's capacity to meet the needs of its farmers [5]. It benefits include but not limited to improved access to information and resources; equipping farmers to make informed decisions on production, marketing of agricultural produce and other farm activities; efficient organizational processes and transactions and better quality value and agricultural productivity satisfaction. Globally, e-agriculture is now acknowledged as a field focused on the improvement of agricultural and rural development by means of information and communication processes [6].

Over the years, ICTs are being used extensively in large-scale farming, but comparatively, little attention has been paid to its utilization for small-scale farming. However, ICTs could help small-scale farmers and other related people in Nigeria and other developing countries attend to a number of the problems and challenges confronting them and improve communication and delivery of important knowledge, information and services. With the proliferation of modest price technology even among the indigent smallholder farmers, there is a huge prospect of utilizing ICT to enhance farm produce, dispense helpful information and in general empower farmers. In Nigeria, mobile phones has proliferated that even in poor rural farmsteads depending on agriculture, there is wide usage of these devices. Mobile phones are easy to use, are progressively able to circumvent the obstacle of illiteracy and affordability and allow access to an ample variety of very useful services that includes surveying market prices, money transfer, getting weather information, acquiring agricultural extension and other expert advice [7].

However, because of the highly localized nature of agriculture, there is a need to investigate the factors that will influence adoption decision and eventual usage when planning to introduce m-Agriculture. This is an essential requirement in order for the evolving system to be tailored towards users' specific and distinct needs and also to circumvent a situation where the evolved system will be not be actually used by the target users. In this paper, an empirical investigation of factors influencing the adoption decision of mobile agriculture by smallholder farmers in rural settings of South-western Nigeria was conducted. The paper extends further by proposing an m-Agriculture architecture could be implemented and adapted in this geographical location.

\section{LITERATURE REVIEW \\ 2.1 ICT as Tools for Agricultural Development}

The author of [8] defined ICT as any tool, device or application: hardware, software and telecommunication options, including the Internet and telephony (mobile and landline) systems, which allows the exchange or collection of data via transmission or interaction. More specifically, ICT is an encompassing term that includes all technologies for the communication of information. The continuous ease of access, fall in price and flexibility of ICT has produced a platform for development innovations, aimed at vital areas of economic and social impact that includes agriculture, education, health and finance.

ICT has initiated new techniques of undertaking many operations by electronic means. Examples include: e-health, e-agriculture, e-commerce, e-banking, e-learning, e-voting, egovernment and so on, mention but a few. Equivalent to this, is also the inventive porting of such these applications to mobile devices; hence m-health, m-agriculture, m-commerce, m-banking, m-learning, m-voting and so on. These applications have greatly altered the way we undertake many activities. There is hardly any section of the world we live in that the changes ICT wrought has not affected. A large majority of people are now habitual users of mobile phones, computer and intense consumers of ICTs. Over the years, governments world over have acted in response by developing ICT policies, setting up regulatory frameworks and initiating institutional infrastructures; with the objective of expediting and bring order to these evolving situations that are speedily altering the world we live in.

In agriculture, its adoption and application can offer a variety of solutions to the numerous agricultural challenges. The functions of ICT in agriculture include 3 agricultural extension and advisory service, disaster management and early warning system, promotion of environmentally sustainable farming practices, food safety and traceability, enhanced market access, capacity buildings and empowerment, transformation of agricultural processes, improved vertical and horizontal linkages, facilitation of information sharing networks, reducing individual and institutional risk, increased food and nutrition security and safety financial inclusion, insurance and risk management, regulatory and policy and so on [9].

\subsection{Mobile Phones: A Trendsetter of ICT in Agriculture}

Mobile phones are just another type of ICT. There exist many channels of ICT that have been utilized to improve agriculture and rural development in general; mass media, Internet and broadband, personal computers, laptops satellites and the list continues. Nevertheless, mobile phones are in the forefront of ICTs in agriculture and rural development. They have been the most accepted and used medium of communication over the world with its infiltration and diffusion more than all other information and communication devices summed together [10]. The rate of penetration of mobile phones exceeds those for internet users, broadband subscriptions and fixed phone lines. The international Telecommunication Union (ITU) in her annual report of 2018 stated that there are 172.7 million mobile-cellular telephone subscription and a penetration rate of 88.18 per 100 inhabitants in Nigeria. When compared to other ICT tools, mobile phones are advantaged in its suitability for the under-developed local conditions. They have been proven to be of immense assistance in enhancing productivity both individually and collectively within resource- constrained settings as it increases efficiency, effectiveness, and access and coverage [1]; [11]; [12].

Mobile phones is the only ICT tool that is not affected by the problem of viability for the poor in geographically deprived locale owning to lack of enabling environments that majorly boarders on infrastructure and capital. As an instance in places where communication networks and electricity is not available or epileptic in supply, the usage of Internet enhanced technologies mighty also be impossible. Conversely, basic mobile phone functionalities such as Voice/ Interactive Voice Response (IVR), short message service (SMS) and Unstructured Supplementary Service Data (USSD) requires less infrastructures, consequently giving rise of broader applicability. A variety of agricultural services can be provided utilizing the aforementioned basic mobile phone functionalities. Other advanced features of mobile phones which facilitate a wider potential of ICT innovations for agriculture includes Internet, Radio-frequency Identification (RFID), Global Positioning System (GPS), Near-field Communication (NFC) and photo and video capturing. Majority of these advanced features are however available on smart phones and features and their deployment for 
agricultural use is usually for targeted users and in places and situations where there is availability of more advanced ICT infrastructure and services.

\subsection{Technology Acceptance Model (TAM)}

In this paper, the Technology Acceptance Model (TAM) which was developed by [13] was applied to investigate the factors influencing the adoption decision to use mobile agriculture. Davis in [13] founded his model on the psychological model, the Theory of Reasoned Action (TRA). TRA is based on the theory that the individual attitude has a significant function in determining the behaviour towards adopting a particular technology [14]. Nevertheless, TAM is widely regarded as a more flexible technique due to its ability to give permission to the capturing of a number of essential psychological elements that influence producers in adopting or not adopting the technology. The model has been appraised to be not only an authoritative model for denoting the determinants of system usage, but it is a helpful tool for system planning, in view of the fact that system designers have to an extent, control over easiness and usefulness [15].

Fig 1 depicts the original TAM. It's an information system acceptance theory, whose core rationale is basically to predict and explicate the user acceptance of information technology. TAM is built from a number of indicators that includes Perceived Ease of Use (PEOU), Perceived Usefulness (PU), Attitudes Towards Using (ATU), Behavioural Intention (BI) and Actual Usage (AU). These indicators are defined as follows: Perceived Usefulness (PU) refers to the extent to which an individual believes that his/her job performance could be improved by utilizing an IT system [13]; [16]; [17]. Perceived Ease of Use (PEOU) is the degree of believe of an individual that the usage of an information technology would be effort free [18]. Attitudes Towards Using (ATU) is defined as a function of beliefs, positively or adversely towards the behaviour [17]; [19]; [20]; [21]. Behavioural Intention (BI) is defined as target objectives and anticipated reaction to the attitude object [17]; [19]; [20]. Actual Usage (AU) is defined by [22] as the rate of utilizing a new technology system, for example, mobile agriculture and the estimated frequency the user uses it over a specific duration [17]; [19]; [20].

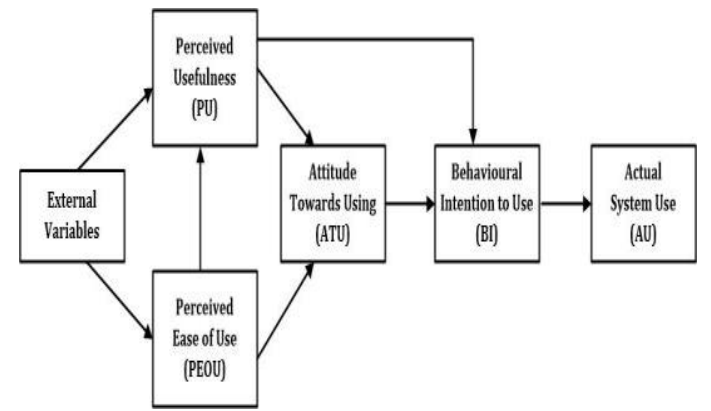

Fig 1: The Original Technology Acceptance Model [13]

It was suggested by a number of researchers that TAM needs to be supplemented by additional variables in order to realize a sturdier model [23]. TAM2 was proposed as an expansion of TAM by [24]. The authors integrated social influence and cognitive instrumental processes, but left out ATU owing to weak predictors of either AU or BI. Their proposition is in consonance with the previous work of [15] which specified that both social influence processes and cognitive instrumental processes extensively determined user acceptance and that PEOU and PU indirectly determined AU through BI.
The focus of this paper is on the investigation of the factors that determines the acceptance of an information and communications technology application, m-Agriculture; consequently, an appraisal of previous studies suggested the theoretical basics of used in the formulated hypotheses of this work. Furthermore, it was highlighted in several research, that it is of significant importance, to incorporate additional variable(s) to TAM so as to enhance its prediction of system use [25]; [26]. Towards this end, the following external variables were introduced to TAM in this paper in investigating the factors that have significant effects on the adoption decision of mobile agriculture amongst smallholder farmers in South-western Nigeria: job relevance, performance expectancy, perceived compatibility, perceived price value and social influence. These variables are defined as follows:

i. Job Relevance: This refers to individual's opinion regarding the degree to which the target system is relevant to his or her job [27].

ii. Performance Expectancy: This measures the degree of an individual's believes that the usage of the system will assist him or her to accomplish gains in job performance [27].

iii. Perceived Compatibility: According to [28], compatibility refers to the degree to which an innovation is seen to be compatible with principles, experiences, beliefs and needs of individuals adopting it. This variable encompasses a user's perception of the comparison of the innovation with their lifestyle.

iv. Perceived price value: Perceived price value can be viewed using two perspectives according to [29]. One, the initial price of acquiring devices (in the context of this work, mobile phones) and two, the price of subscribing both from the mobile network provider and the service provider. These authors defined this variable as the willingness to pay for a service.

v. Social influence: Fishbein and Ajzen, in [19] defined this variable as the perceived external pressure that is felt by individuals in the course of being in the knowing of an innovation and the decision to utilize it, and the degree in which an individual perceives that important others believe he or she should use the new system.

\section{RESEARCH METHODOLOGY 3.1 Proposed Research Model and Hypotheses Formulation}

Fig 2 depicts the proposed research model of this work. The model integrates external variables that include Job Relevance (JR), Performance Expectancy (PE), Perceived Compatibility (PC), Perceived Price Value (PPV) and Social Influence (SI) to the original TAM.

Consequently, after evolving the research model of this work, there is the need to formulate and test hypothesis in order to establish the effects of the introduced external variables and their corresponding relationship with the original TAM. The formulated hypotheses are as follows:

i. $\mathrm{H}_{1}$ : Behavioural intention to use m-Agriculture has a direct effect on the future actual use of $\mathrm{m}$ Agriculture.

ii. $\mathrm{H}_{2}$ : Job relevance has a direct effect on behavioural intention to use m-Agriculture.

iii. $\mathrm{H}_{3}$ : Performance expectancy has a direct effect on behavioural intention to use m-Agriculture.

iv. $\mathrm{H}_{4}$ : Perceived price value has a direct effect on 
behavioural intention to use m-Agriculture.

v. $\mathrm{H}_{5}$ : Social influence has a direct effect on behavioural intention to use m-Agriculture.

vi. $\mathrm{H}_{6}$ : Perceived compatibility has a direct effect on behavioural intention to use m-Agriculture.

vii. $\mathrm{H}_{7}$ : Perceived usefulness has a direct effect on behavioural intention to use m-Agriculture.

viii. $\mathrm{H}_{8}$ : Perceived ease of use has a direct effect on behavioural intention to use m-Agriculture.

ix. $\quad \mathrm{H}_{9}$ : Perceived ease of use has a direct effect on perceived usefulness of the usage of $\mathrm{m}$-Agriculture.

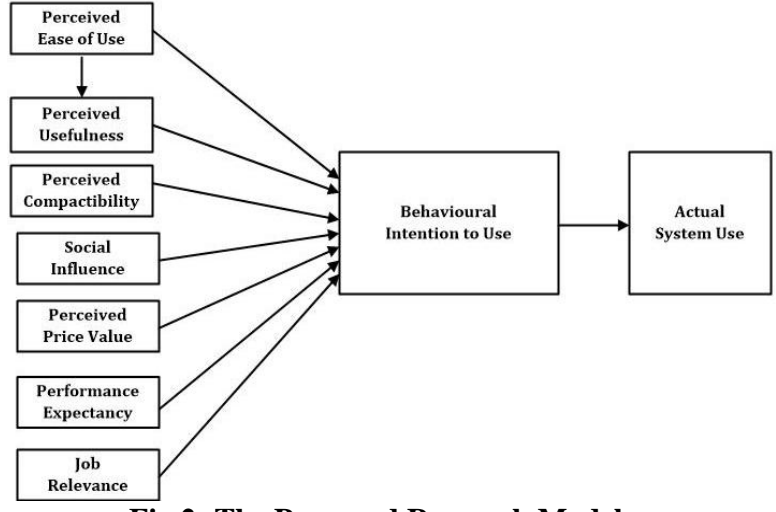

Fig 2: The Proposed Research Model

The proposed research model for introducing the adoption of $\mathrm{m}$-Agriculture to smallholder farmers in South-western Nigeria with the hypothesized paths is depicted in Fig 3.

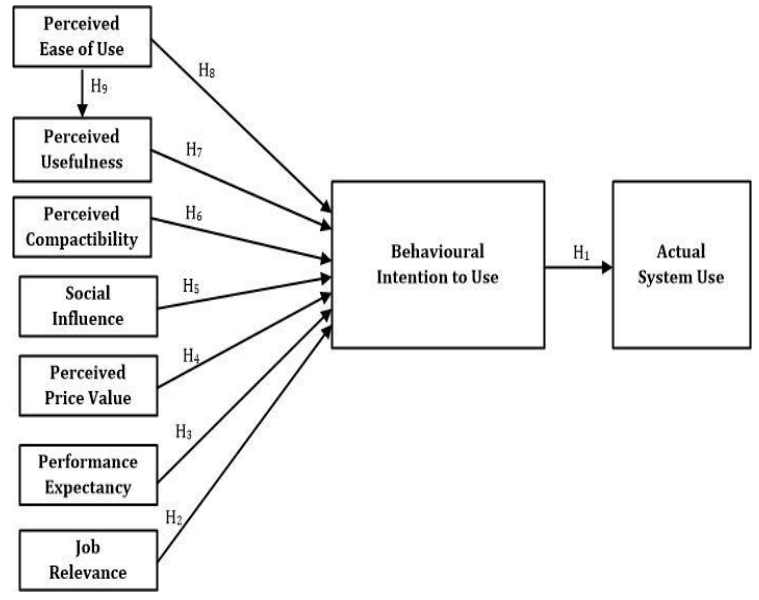

Fig 3: The Proposed Model with Hypothesized Paths

\subsection{Data Collection}

The participants (randomly selected) used for this research are smallholder farmers taken from twelve farming communities in the neighbourhood of Ogbomoso and selected farming communities in Oke-ogun area of Oyo State, Nigeria. The selection was based on gender, age, basic/feature mobile phone ownership and crop farm ownership. Yin in [30] proposed methods for case study research. Two of these methods, direct observation and field interviews were adopted in this research. The selected participants were enlightened on advantages and usefulness of mobile phones in agriculture and the possible changes agricultural based mobile applications can bring to their livelihood. A questionnaire consisting of 25 items on a five-point Likert rating scale was administered to interview 140 smallholder farmers practicing crop farming.
The opinions of the respondents on the perceived relative advantages (that includes the maintenance of kinship networks and agricultural purposes, including the abilities to access financial information, and to efficiently coordinate meetings and consult with agriculture extension agents or farm group members) that led to their initial adoption of mobile phone were also collected during the interviews. The responses were filled out by the researchers due to the literacy level of some of the respondents. The descriptive analysis of respondent was carried out using Social Science software (SPSS) v.20 while the formulated hypotheses were tested using partial least square structural equation analysis.

\section{RESULTS AND DISCUSSION 4.1 Descriptive Statistical Analysis of Respondents}

A questionnaire consisting of 25 items on a five-point Likert rating scale was utilized to collect the data used in this research. The items on the questionnaire describe the nine variables which are AU, BI, PEOU, PU, JR, PE, PC, PPV and SI. Out of the 140 smallholder farmers practicing crop farming that were interviewed, only 118 of the farmers gave complete responses.

This sub-section presents the descriptive statistical analysis of the socio-demographic characteristics of the respondents. The analysis showed that $82 \%$ of the respondents were male. Pertaining to the age of the respondents, $13.56 \%$ were in the age bracket of $18-25$ years; $22.79 \%$ within $26-35$ years; $31.65 \%$ were aged between $36-45$ years; $18.41 \%$ falls inside the range of $46-55$ years while $10.72 \%$ of the respondents were of 56-65 years of age. The remaining $2.87 \%$ of the respondents were of age 66 years and over. Regarding educational level, $52.04 \%$ of the respondents were of Primary school level; $45.78 \%$ completed Secondary school while $2.18 \%$ of them were educated up to tertiary level. On the type of mobile phone owned by the respondent, $76.05 \%$ owned basic/feature phones while other owned Smart phones. Table 1 details the descriptive statistics related to the variables utilized in the model. The mean of every variable is greater than the average value, 3 , which consequently interprets that the respondents strongly agree or agree that the measured variables will be determinants in their consideration of the adoption and eventual use of mobile agriculture applications

Table 1: Descriptive Statistical Analysis of Model Variables

\begin{tabular}{|l|c|c|c|c|}
\hline \multicolumn{1}{|c|}{ Variable } & $\mathbf{N}$ & Range & Mean & SD \\
\hline Job Relevance & 118 & 5 & 3.94 & 1.09 \\
\hline Performance Expectancy & 118 & 5 & 3.82 & 1.15 \\
\hline $\begin{array}{l}\text { Perceived } \\
\text { Price Value }\end{array}$ & 118 & 5 & 3.46 & 1.06 \\
\hline Social Influence & 118 & 5 & 4.01 & 1.12 \\
\hline Perceived Compatibility & 118 & 5 & 3.69 & 0.82 \\
\hline Perceived usefulness & 118 & 5 & 3.98 & 0.79 \\
\hline $\begin{array}{l}\text { Perceived } \\
\text { Ease of Use }\end{array}$ & 118 & 5 & 3.81 & 1.14 \\
\hline $\begin{array}{l}\text { Behavioural } \\
\text { Intention to Use }\end{array}$ & 118 & 5 & 3.97 & 0.94 \\
\hline Actual System Use & 118 & 5 & 3.73 & 1.16 \\
\hline
\end{tabular}

\subsection{Internal Consistency Analysis of}

\section{Variables}

A post-data collection analysis was carried out to test for the internal consistency of the Likert rating scale items on the questionnaire using Cronbach's alpha reliability coefficient. These Likert scale items were group differently into nine to 
form the nine variable used in the model. The reliability coefficients of the nine groups depicting the nine variable of the model were measured. The values of the alpha reliability are presented in Table 2.

Table 2: Cronbach's $\alpha$ Internal Consistency Analysis

\begin{tabular}{|l|c|c|}
\hline \multicolumn{1}{|c|}{ Variable } & $\begin{array}{c}\text { Number } \\
\text { of Items }\end{array}$ & Cronbach's $\boldsymbol{\alpha}$ \\
\hline Job Relevance & 3 & 0.7726 \\
\hline $\begin{array}{l}\text { Performance } \\
\text { Expectancy }\end{array}$ & 2 & 0.7358 \\
\hline Perceived Price Value & 3 & 0.8107 \\
\hline Social Influence & 3 & 0.7821 \\
\hline $\begin{array}{l}\text { Perceived } \\
\text { Compatibility }\end{array}$ & 3 & 0.8228 \\
\hline Perceived usefulness & 3 & 0.7815 \\
\hline Perceived Ease of Use & 3 & 0.7314 \\
\hline
\end{tabular}

\begin{tabular}{|l|c|c|}
\hline $\begin{array}{l}\text { Behavioural } \\
\text { Intention to Use }\end{array}$ & 3 & 0.7962 \\
\hline Actual System Use & 2 & 0.8125 \\
\hline
\end{tabular}

The values ranged between 0.7314 and 0.8228 which indicated that the data collected through the rating scale have satisfactory reliability, with values above 0.7 which is considered as adequate benchmark for survey items [31]

\subsection{Variables' Reliability and Validity}

As earlier mentioned, the formulated hypotheses were tested using PLS structural equation analysis. In the PLS analysis, the reliability of the variables was evaluated using the composite reliability and Average Variance Extracted (AVE) for each variable. This is presented in Table 3. According to [32], a value of 0.7 or higher is the acceptable benchmark.

Table 4: Fornell and Larcker Criterion

\begin{tabular}{|l|c|c|c|c|c|c|c|c|c|c|}
\hline & Variable & $\mathbf{1}$ & $\mathbf{2}$ & $\mathbf{3}$ & $\mathbf{4}$ & $\mathbf{5}$ & $\mathbf{6}$ & $\mathbf{7}$ & $\mathbf{8}$ & $\mathbf{9}$ \\
\hline 1 & $\begin{array}{c}\text { Job } \\
\text { Relevance }\end{array}$ & $\mathbf{0 . 9 2 2}$ & & & & & & & & \\
\hline 2 & $\begin{array}{c}\text { Performance } \\
\text { Expectancy }\end{array}$ & 0.598 & $\mathbf{0 . 8 5 9}$ & & & & & & & \\
\hline 3 & $\begin{array}{c}\text { Perceived } \\
\text { Price Value }\end{array}$ & 0.472 & 0.613 & $\mathbf{0 . 8 6 8}$ & & & & & & \\
\hline 4 & Social Influence & 0.601 & 0.552 & 0.570 & $\mathbf{0 . 9 5 2}$ & & & & & \\
\hline 5 & $\begin{array}{c}\text { Perceived } \\
\text { Compatibility }\end{array}$ & 0.535 & 0.519 & 0.611 & 0.609 & $\mathbf{0 . 8 9 6}$ & & & & \\
\hline 6 & $\begin{array}{c}\text { Perceived } \\
\text { Usefulness }\end{array}$ & 0.612 & 0.633 & 0.498 & 0.597 & 0.702 & $\mathbf{0 . 8 3 7}$ & & & \\
\hline 7 & $\begin{array}{c}\text { Perceived Ease of } \\
\text { Use }\end{array}$ & 0.498 & 0.502 & 0.536 & 0.562 & 0.619 & 0.686 & $\mathbf{0 . 9 0 3}$ & & \\
\hline 8 & $\begin{array}{c}\text { Behavioural } \\
\text { Intention to Use }\end{array}$ & 0.603 & 0.558 & 0.482 & 0.613 & 0.589 & 0.702 & 0.597 & $\mathbf{0 . 8 8 6}$ & \\
\hline 9 & $\begin{array}{c}\text { Actual System } \\
\text { Use }\end{array}$ & 0.502 & 0.497 & 0.589 & 0.611 & 0.547 & 0.595 & 0.494 & 0.786 & $\mathbf{0 . 9 0 6}$ \\
\hline
\end{tabular}

Therefore, from Table 3, the composite reliability values for each variable showed that all the variables exhibit acceptable degree of internal consistency. The other reliability measure utilized in the PLS analysis is the AVE. This reliability measure indicates the total amount of variance in the items catered for by the underlying variable [33]. When compared with composite reliability, the AVE is a more conservative reliability measure, hence, an acceptable benchmark value of 0.5 or higher is suggested for AVE by [34]. From Table 3, all the variables surpassed this criterion.

Table 3: Variable Reliability Coefficients

\begin{tabular}{|l|c|c|}
\hline \multicolumn{1}{|c|}{ Variable } & $\begin{array}{c}\text { Composite } \\
\text { Reliability }\end{array}$ & AVE \\
\hline Job Relevance & 0.9124 & 0.8502 \\
\hline Performance Expectancy & 0.8292 & 0.7376 \\
\hline Perceived Price Value & 0.8417 & 0.7529 \\
\hline Social Influence & 0.8823 & 0.8061 \\
\hline Perceived Compatibility & 0.8911 & 0.8125 \\
\hline Perceived usefulness & 0.8602 & 0.7613 \\
\hline Perceived Ease of Use & 0.9005 & 0.8148 \\
\hline $\begin{array}{l}\text { Behavioural Intention to } \\
\text { Use }\end{array}$ & 0.8327 & 0.7846 \\
\hline Actual System Use & 0.8914 & 0.8217 \\
\hline
\end{tabular}

Aside reliability measurement, the AVE can in addition be utilized in the evaluation of discriminant validity (Fornell and Larcker 1981). An essential requirement for the satisfactory evaluation of the discriminant validity is that the square root of the AVE of each variable must be greater than the correlations between the variables and every other variable. Table 4 details the results. Clearly from this table, the correlations between the variables are less than the square root of AVE of their respective variables.

\subsection{Testing the Significance of the Hypotheses}

Table 5 shows the results of the hypotheses tests and the standardized $\beta$ coefficient of the research model proposed in this work. Through the standardized $\beta$ coefficient, the significance of the hypothesis was tested. The expected variation in the dependent variable for a unit variation in the independent variables (s) is indicated by $\beta$ value. The $\beta$ value was computed for each path in the mode. It may be noted that the higher the value of $\beta$, the better the significant effect on the latent variable. All the hypotheses were supported by the data. The significant structural relationship among the research variables and the standardized $\beta$ coefficients for each independent variable is depicted in Fig 4. 
Table 5: Hypotheses Testing Results

\begin{tabular}{|c|c|c|c|c|}
\hline Hypo. & Path & $\boldsymbol{\beta}$ & p-value & Results \\
\hline $\mathrm{H}_{1}$ & $\mathrm{BI} \rightarrow \mathrm{AU}$ & 0.854 & $<0.001$ & Supported \\
\hline $\mathrm{H}_{2}$ & $\mathrm{JR} \rightarrow \mathrm{BI}$ & 0.095 & $<0.05$ & Supported \\
\hline $\mathrm{H}_{3}$ & $\mathrm{PE} \rightarrow \mathrm{BI}$ & 0.183 & $<0.01$ & Supported \\
\hline $\mathrm{H}_{4}$ & $\mathrm{PPV} \rightarrow \mathrm{BI}$ & 0.098 & $<0.05$ & Supported \\
\hline $\mathrm{H}_{5}$ & $\mathrm{SI} \rightarrow \mathrm{BI}$ & 0.195 & $<0.001$ & Supported \\
\hline $\mathrm{H}_{6}$ & $\mathrm{PC} \rightarrow \mathrm{BI}$ & 0.168 & $<0.001$ & Supported \\
\hline $\mathrm{H}_{7}$ & PU $\rightarrow \mathrm{BI}$ & 0.302 & $<0.001$ & Supported \\
\hline $\mathrm{H}_{8}$ & PEOU $\rightarrow \mathrm{BI}$ & 0.201 & $<0.001$ & Supported \\
\hline $\mathrm{H}_{9}$ & PEOU $\rightarrow \mathrm{PU}$ & 0.711 & $<0.001$ & Supported \\
\hline
\end{tabular}

From Table 5, it can be deduced that behavioural intention to use mobile agriculture has a significant and positive influence on its actual use. Job relevance has a significant and direct effect on the intention to use m-Agriculture but indirectly influences its actual use. For hypothesis 3, performance expectancy directly and significantly influences the behavioural intention to use. The postulation of hypothesis 4 , that is, perceived price values significantly and directly having behavioural intention to use mobile agriculture, is also supported by the data. Social influence however has a positive, direct and significant influence on behavioural intention to use. Similarly, perceived compatibility has a direct and significant influence on behavioural intention to use $\mathrm{m}$-Agriculture but indirectly determines it actual use. For hypothesis 7 , perceived usefulness positively and significantly influence the behavioural intention to use m-Agriculture but indirectly determines it actual use. As shown by the data, perceived ease of use of m-Agriculture amongst smallholder farmers in Southwestern Nigeria, has a significant effect on behavioural intention to use and a direct effect on it perceived usefulness.

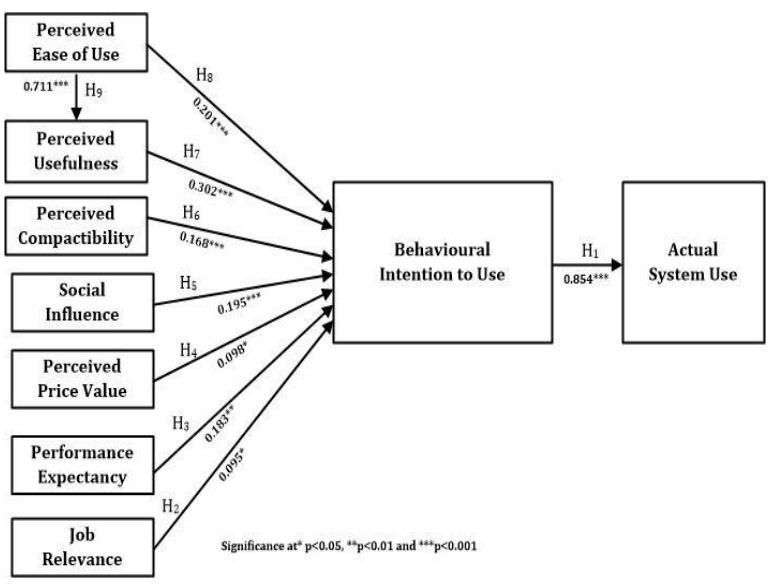

Fig 4: Structural Model: Result of PLS Analysis

\subsection{Proposed m-Agriculture Architecture}

Fig 5 depicts the m-Agriculture architecture proposed by the authors. The architecture was based on the needs of the respondents and on the results of the empirical investigation of the factors that determines their adoption decision of $\mathrm{m}$ Agriculture. The technology available to them, the technological infrastructures they are exposed to and their geographical location were taken into cognizance. Three communication channels of a basic/feature phone, which are voice, SMS and USSD were suggested for content delivery while actual communication will be facilitated by existing mobile telecommunication infrastructures. Communication between farmers and extension workers, agro input dealers and so on is habitually catered for by the proposed architecture. The m-Agriculture application runs at the end on the application and database servers. These servers interface the users (farmers, extension workers, afro-dealer and so on) to the m-Agriculture services to be provided by the architecture. Furthermore, contents providers are interfaced with the architecture via these servers.

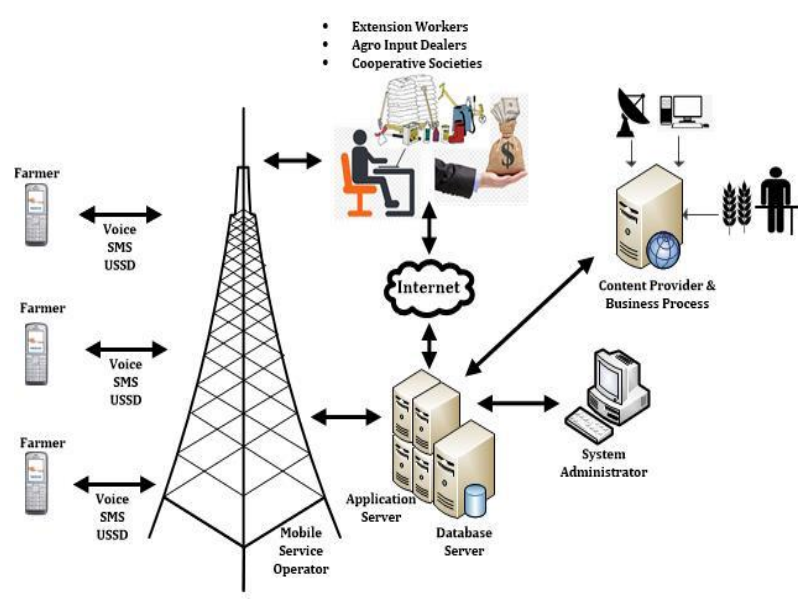

Fig 5: Proposed m-Agriculture Architecture

\section{CONCLUSION}

In this paper, an empirical investigation of factors influencing the adoption decision of mobile agriculture in Southwestern Nigeria was carried out by extending the TAM through the incorporation of external variables that include job relevance, performance expectancy, perceived compatibility, perceived price value and social influence to the original TAM variables. The results obtained supported all the formulated hypotheses.

Job relevance has an essentially important direct effect on the farmers' behavioural intention to adopt and use of $\mathrm{m}$ Agriculture as the data showed that they believed mAgriculture applications is highly relevant to their type of farming. Similarly, performance expectancy directly influences the behavioural intention to use m-Agriculture amongst these farmers as the data showed that they were of the opinion the using m-Agriculture will be of assistance to accomplish gains in job performance.

Like other external variables, perceived price value was found by this study to have a significant and direct effect on behavioural intention to use $\mathrm{m}$-Agriculture. This means that the cost of acquisition or usage of the technology will be a determinant on whether the respondents will adopt or use mAgriculture. Correspondingly, social influence has a direct influence on behavioural intention to use m-Agriculture but indirectly determines it actual use. This translates that there is a high perception by the respondents that important others believe they should use the new system. Also, perceived compatibility has a direct and significant influence on behavioural intention to use m-Agriculture. It is suggested that in developing m-Agriculture solutions, attention to details on needs assessment and requirements analysis for the target population should be utmost consideration of information system developers. When introducing a new technology, the target user tends to adopt and accept the technology more easily when they have better perceptions that it is compatible with beliefs, experiences, principle and previous/present practices.

Another essential determinant variable is perceived usefulness. This variable has a direct and significant influence 
on determining the farmers has behavioural intention to adopt and use of m-Agriculture in Southwestern Nigeria. On the variable, perceived ease of use, it is an integral determinant for predicting the farmers 'behavioural intention to adopt and use of m-agriculture. Results obtained from the formatted hypotheses involving this variable showed that there is a greater tendency for wider adoption of the technology if it is easy to use and more user-centric.

The results showed that the farmers' behavioural intentions to use m-Agriculture is dictated by job relevance, performance expectancy, perceived compatibility, perceived price value, social influence, perceived usefulness and perceived ease of use. Also, the results translates that the behavioural intention to use has a direct effect on the actual use of m-Agriculture.

Conclusively, this paper can serve as a guide to information systems designers and developers in the requirements definition stage when designing $\mathrm{m}$-Agriculture applications that is contextual to sub-Saharan African countries so as not to end up in designing or developing systems that will not be adoptable or utilized by the target users. Furthermore, the proposed m-Agriculture architecture could be implemented and adapted in sub-Saharan African countries for improved agricultural productivity, efficiency and sustainability.

\section{REFERENCES}

[1] Okediran, O.O., Ganiyu, R.A. and Badmus, T.A. 2018. An m-Agriculture framework for agriculture information services delivery, LAUTECH Journal of Engineering and Technology 12(2):72-79.

[2] Okediran, O.O. 2019. An e-Agriculture framework for inclusive agricultural values chains in Nigeria, Annals. Computer Science Series, Tibiscus University of Timisoara, Romania, 17(2): 2009 - 2019.

[3] Miller, C., Saroja, V.N. and Linder C. 2013. ICT Uses for Inclusive Agricultural Value Chains. FAO, Rome.

[4] Awuor, F., Kimeli, K., Rabah, K. and Rambim, D. 2013. ICT Solution Architecture for Agriculture, IST-Africa 2013 Conference Proceedings Paul Cunningham and Miriam Cunningham (Eds) IIMC International Information Management Corporation.

[5] Namisiko, P. and Aballo, M. 2013. Current Status of eAgriculture and Global Trends: A Survey Conducted in TransNzoia County, Kenya, International Journal of Science and Research, India, 2(7): 18-22.

[6] Meera, S., Jhamtani, A. and Rao, D.U.M. 2004. Information and communication technology in agricultural development: A comparative analysis of three projects from India, Agricultural Research and Extension Network, Network Paper No. 135, pp 1-20.

[7] ICT Updates 2013. e-Agriculture Strategies”, Issue 73, Available at https://cgspace .Cigar. org/bitstream /handle/ 10568/75314/ICT073E_PDF.pdf?sequence= $1 \&$ is Allowed=y.

[8] Mcnamara, K.., Belden, C., Kelly, T., Pehu, E. and Donovan, K. 2011. Introduction: ICT in Agricultural Development, ICT in Agriculture. The World Bank.

[9] Okediran, O.O. and Ganiyu, R.A. 2019. e-Agriculture reviewed: Theories, concepts and trends, FUOYE Journal of Engineering and Technology, 4(1):125-130.

[10 Okediran, O.O., Omidiora, E.O., Olabiyisi, S.O. and Ganiyu, R.A. 2013. An M-voting System Framework for
Electronic Voting, Proceedings of the Second International Conference on Engineering and Technology Research, Lautech, Ogbomoso, Nigeria.

[11] Burrell, J. 2008. Livelihoods and the Mobile Phone in Rural Uganda. Retrieved from http://www. Rameen foundation.applab.org/section/ethnographic-research

[12] Qiang, C.Z., Kuek, S.C., Dymond, A. and Esselaar, S. 2012. Mobile Applications for Agriculture and Rural Development, ICT Sector Unit World Bank, Washington D.C.

[13] Davis, F. 1989, Perceived Usefulness, Perceived ease of use and user acceptance of information technology, MIS Quarterly, 13(3): 318-339.

[14] 4Ajzen, I. and Fishbein, M., 1980. Understanding Attitudes and Predicting Social Behaviour. Prentice-Hall, Englewood Cliffs, New Jersey.

[15] Taylor, S. and Todd, P. 1995. Understanding information technology usage: A test of competing models, Information Systems Research, 6(2):143-176.

[16] Davis, F.D., Bagozzi, R.P. and Warshaw, P.R. 1989. User acceptance of computer technology: A comparison of two theoretical models, Management Science 35, 982 1003.

[17] Davis, F.D. and Cosenza, R.M. 1993. Business Research for Decision Making. Third Edition. Belmont, CA. Wadsworth Inc.

[18] Adams, D., Nelson, R. and Todd, P. 1992. Perceived usefulness, ease of use, and usage of information technology: A replication', MIS Quarterly, 16(2): 227247.

[19] Fishbein, M. and Ajzen, I. 1975. Belief, Attitude, Intentions and Behaviour: An Introduction to Theory and Research. Addison-Wesley, Boston.

[20] Fishbein, M. and Ajzen, I. 1979. A Theory of Reason Action: Some Applications and Implications, in Howe H. and Page M. (Eds): Nebraska Symposium on Motivation, University of Nebraska Press, Lincoln, NB, pp.65-116.

[21] Yogesh, M. and Dennis, F. 1999. Extending the Technology Acceptance Model to Account for Social Influence: Theoretical Bases and Empirical Validation', Thirty-Second Annual Hawaii International Conference on System Sciences, IEEE.

[22] Chen, L., Gillenson, M. and Sherrell, D. 2002. Enticing online consumers: an extended technology acceptance perspective, Information and Management,39(8):705719.

[23] Legris, P., Ingham, J. and Collerette, P. 2003. Why Do People Use Information Technology? A Critical Review of the Technology Acceptance Model, Information \& Management, 40(3):191-204.

[24] Venkatesh, V. and Davis, F. 2000. A theoretical extension of the technology acceptance model: Four longitudinal field studies, Management Science, 46(2): 186-204.

[25] Szajna, B. 1996. Empirical Evaluation of the revised technology acceptance model, Management Science, 42(1): 85-92.

[26] Lucas, H.C. and Spitler, V.K. 2000. Implementation in a 
world of workstations and networks, Information \& Management, 38(2): 119-128.

[27] Venkatesh V. and Bala H. 2008. Technology acceptance model 3 and a research agenda on interventions". Decision sciences, 39(2):273-315.

[28] Rogers, E.M. 1995. Diffusion of Innovations. The Free Press, New York.

[29] Cheong, J. and Park, M. 2005. Mobile Internet Acceptance in Korea, Internet Research: Electronic Networking Applications and Policy, 15:.125-140.

[30] Yin R.K. 1984. Case Study Research: Design and Methods. Sage Publications, Beverly Hills, California.

[31] DeVellis R.F. 1991. Scale Development. Newbury Park,
CA: Sage Publications.

[32] Thompson. R.L., Higgins, C.A. and Howell, J.M. 1995. Influence of experience on personal computer utilization: Testing a conceptual model, Journal of Management Information Systems, 11(1): 167-187.

[33] Cheung, C. and Lee, M. 2000. Trust in Internet Shopping: A Proposed Model and Measurement Instrument", Proceedings of the Sixth Americas Conference in Information Systems, August 10-13, 2000 , Long Beach, CA.

[34] Fornell, C. and Larcker, D.F. 1981, Evaluating structural equation models with unobservable variables and measurement error, Journal of Marketing Research, 18 : $39-50$. 